\title{
The Isentrope of Unreacted LX-04 to 170 kbar
}

D.E. Hare, D.B. Reisman, F. Garcia, J.W. Forbes, M.D. Furnish, C. Hall, R.J. Hickman

This article was submitted to American Physical Society Topical Conference on Shock Compression of Condensed Matter Portland, OR July 20-25, 2003

\section{July 15, 2003}




\section{DISCLAIMER}

This document was prepared as an account of work sponsored by an agency of the United States Government. Neither the United States Government nor the University of California nor any of their employees, makes any warranty, express or implied, or assumes any legal liability or responsibility for the accuracy, completeness, or usefulness of any information, apparatus, product, or process disclosed, or represents that its use would not infringe privately owned rights. Reference herein to any specific commercial product, process, or service by trade name, trademark, manufacturer, or otherwise, does not necessarily constitute or imply its endorsement, recommendation, or favoring by the United States Government or the University of California. The views and opinions of authors expressed herein do not necessarily state or reflect those of the United States Government or the University of California, and shall not be used for advertising or product endorsement purposes.

This is a preprint of a paper intended for publication in a journal or proceedings. Since changes may be made before publication, this preprint is made available with the understanding that it will not be cited or reproduced without the permission of the author.

This report has been reproduced directly from the best available copy.

Available electronically at http://www.doc.gov/bridge

Available for a processing fee to U.S. Department of Energy

And its contractors in paper from

U.S. Department of Energy

Office of Scientific and Technical Information

P.O. Box 62

Oak Ridge, TN 37831-0062

Telephone: (865) 576-8401

Facsimile: (865) 576-5728

E-mail: reports@adonis.osti.gov

Available for the sale to the public from

U.S. Department of Commerce

National Technical Information Service

5285 Port Royal Road

Springfield, VA 22161

Telephone: (800) 553-6847

Facsimile: (703) 605-6900

E-mail: orders@ntis.fedworld.gov

Online ordering: http://www.ntis.gov/ordering.htm

OR

Lawrence Livermore National Laboratory

Technical Information Department's Digital Library

http://www.llnl.gov/tid/Library.html 


\title{
THE ISENTROPE OF UNREACTED LX-04 TO $170 \mathrm{kbar}$
}

\author{
D.E. Hare ${ }^{1}$, D.B. Reisman ${ }^{1}$, F. Garcia ${ }^{1}$, J.W. Forbes ${ }^{1}$, \\ M.D. Furnish ${ }^{2}$, Clint Hall ${ }^{2}$, R.J. Hickman² \\ ${ }^{1}$ Lawrence Livermore National Laboratory, Livermore, CA 94550 \\ ${ }^{2}$ Sandia National Laboratory, Albuquerque, NM 87185
}

\begin{abstract}
We present new data on the unreacted approximate isentrope of the HMX-based explosive LX-04, measured to $170 \mathrm{kbar}$, using newly developed long pulse isentropic compression techniques at the Sandia National Laboratories Z Machine facility. This study extends in pressure by $70 \%$ the previous state of the art on unreacted LX-04 using this technique. This isentrope will give the unreacted Hugoniot from thermodynamic relations using a Gruneisen equation of state model. The unreacted Hugoniot of LX-04 is important in understanding the structure of the reaction front in the detonating explosive. We find that a Hugoniot given by $U_{\mathrm{S}}=2950 \mathrm{~m} / \mathrm{s}+1.69 u_{\mathrm{P}}$ yields for an isentrope a curve which fits our LX-04 ICE data well.
\end{abstract}

\section{INTRODUCTION}

LX-04 is an important weapons-related secondary high explosive formulation composed of $85 \%$ HMX (octahydro-1,3,5,7-tetranitro1,3,5,7-tetrazocine) and $15 \%$ Viton-A (vinylidene fluoride/hexafluoropropylene copolymer) [1]. The unreacted Hugoniot of LX-04 is important for a detailed understanding of the impulse it will deliver during detonation. It is difficult to measure the properties of unreacted explosives by conventional shock compression techniques, which tend to initiate detonation. On the other hand, ramp wave compression, such as is achieved in Isentropic Compression Experiments (ICE), is believed to be inherently a lower temperature dynamic loading process than shock compression. The ICE technique has already been demonstrated to be very effective at dynamically loading high explosives without reaction, and experiments have already been performed on LX-04 as well as various other explosives [2,3]. The previous
ICE work on LX-04 extended to $100 \mathrm{kbar}$ [2], but recent improvements in waveform shaping motivated us to attempt to remeasure the LX-04 isentrope to higher pressures.

Our ICE experiments were conducted at Sandia National Laboratories $\mathrm{Z}$ Machine facility. The ICE technique [4,5] generates a large-amplitude (hundreds of kbar) compression wave of a few hundreds of nanosecond rise time (by comparison, shock wave rise times can be sub-nanosecond). This ramp wave is launched into the sample by magnetic pressure developed by an enormous current density in a conductive "floor" upon which the sample is mounted (For all our samples this floor was $800 \mu \mathrm{m}$ of 6061aluminum.). This current creates a timedependent pressure boundary condition on the interior floor interface (the $a-b$ interface of Fig. 2). References 4 and 5 contain excellent descriptions of this versatile technique.

\section{PROCEDURE}


Full density LX-04 samples of six different thicknesses and two $\mathrm{NaCl}$ (100) samples were mounted on four panels made from 6061 aluminum. Each panel is precision machined to $800 \mu \mathrm{m}$ thick in three places. Thus each panel will accommodate three samples. All samples used a $\mathrm{NaCl}$ (100) VISAR window. In addition, four $\mathrm{LiF}$ (100) windows were mounted, one per panel, directly on the Al floor to monitor the drive uniformity between panels. $\mathrm{NaCl}$ is a better acoustic impedance match to $\mathrm{HE}$ than the more popular LiF but it has a phase transition at about 260 kbar [6]. However, this limitation does not impact our data as $260 \mathrm{kbar}$ is still beyond the pressure range of this work. Commercially available VALYN VISAR equipment was used. The refractive indexdensity relations of Wackerle and Stacy [6] were used for the $\mathrm{NaCl}$ windows. Figure 1 shows the four panels with mounted samples. Current flow is in the same direction as the line of samples. Figure 2 is a diagram illustrating an individual sample assembly.

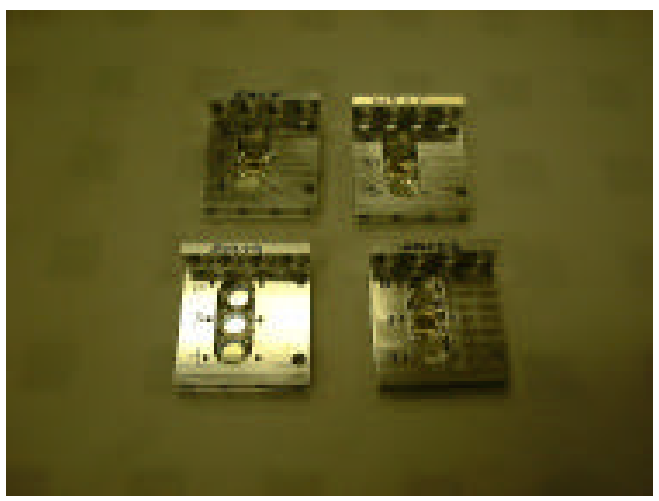

FIGURE 1. The four panels with samples and windows mounted (twelve sample locations total). To give an idea of size, the windows are $6.00 \mathrm{~mm}$ diameter.

\section{RESULTS/DISCUSSION}

The ICE load curve in P-V space was computed based on the work of Fowles and Williams [7]:

$$
\begin{aligned}
& c_{L}(u)=\frac{x_{01}-x_{02}}{t_{1}(u)-t_{2}(u)} \\
& d P=\rho_{0} c_{L}(u) d u \\
& \left(\frac{\partial P}{\partial \rho}\right)_{S}=c_{E}^{2}=\frac{\rho_{0}^{2}}{\rho^{2}}\left(c_{L}(P)\right)^{2} \quad \text { (Eq. } \quad \text { Eq. 3) }
\end{aligned}
$$

In these equations: $c_{\mathrm{L}}$ is the Lagrange sound speed. $u$ is the sample particle velocity. $x_{01}$ is the inital thickness of sample $1, t_{1}$ is the arrival time of the wave of amplitude $u$ at the VISAR interface of sample $1 . \rho_{0}$ and $\rho$ are initial density and density respectively, and $c_{\mathrm{E}}$ is the Eulerian sound speed. Equation 1 is nothing

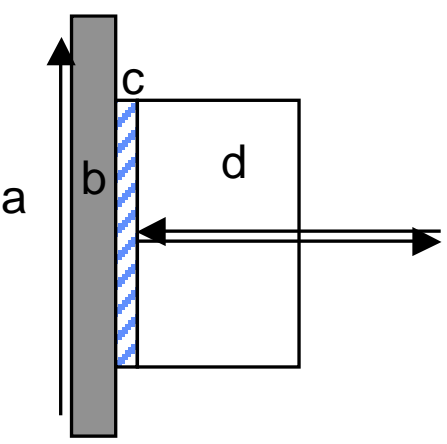

FIGURE 2. Side cut-away view of sample assembly. a) The assembly interior. It can be thought of as the interior of a short-circuited waveguide where a large magnetic field is developed by the current. b) the aluminum floor. The large surface current (vertical arrow) flows at the boundary between "a" and "b". The return conductor (known as the "stem") is to the left of "a" and is not shown. The floor serves both as a conductor for the current and to drive the ramp wave in the sample. c) the sample. d) the window. The interface between "c" and "d" is coated with 250 $\mathrm{nm}$ of silver to efficiently reflect the VISAR probe light, represented by the horizontal arrows. 
more than a recipe for calculating $c_{\mathrm{L}}$ from VISAR data. Equation 2 allows us to eliminate the variable $u$ in favor of the more useful $P$. Equation 3 is then integrated to get the isentrope. We do not consider material strength and do not distinguish between longitudinal wave stress and pressure $P$. A minimal data set for an analysis is two VISAR velocity histories from samples of the same material but of different initial thicknesses. Such an "EOS (equation of state) pair" of histories is represented by Fig. 3, for example. All LX-04 histories showed no clear evidence of reaction and looked quite similar to the histories of the (nonreactive) $\mathrm{NaCl}$.

Equations 1-3 are appropriate to plane isentropic simple wave loading, and finite reflection from the sample-window interface spoils the simple wave assumption. Our window material $\mathrm{NaCl}$ is well (but not perfectly) matched to LX-04. We corrected $u$ using $\mathrm{NaCl}$ and LX-04 Lagrange sound speeds measured in this experiment. Hayes [8] elaborates on the zero-order nature of this type of correction, which according to his Fig. 1 leads to a $10 \%$ error in the worst case scenario (i.e. free surface). However, given that our zero-order correction increased $u$ by less than $10 \%$ over its full range, we estimate 1-2\% error in neglecting the higher order corrections for our specific case.

Unfortunately all our LX-04 waveforms shocked up slightly at the base. We treated the shock as setting up an initial state to a pressure given by the average strength shown in the two waveforms used to create a data set. This average initial shocked state is the starting point for the integration of Eqs. 2 and 3. The results of such a computation performed on our data are displayed in Fig. 4. Also shown in Fig. 4 is a linear (in $U_{\mathrm{S}}, u_{\mathrm{P}}$ ) Hugoniot (dashed line) and the associated isentrope (solid line) derived from this Hugoniot using a Gruneisen gamma model with the constant gamma/volume assumption. We used a $\Gamma_{0}$ of 1.25 based on thermodynamic data [1]. Based on the good agreement between the derived isentrope and our data we conclude that the Hugoniot given by $U_{\mathrm{S}}=2950 \mathrm{~m} / \mathrm{s}+$ $1.69 u_{\mathrm{P}}$ represents the unreacted Hugoniot data for full density LX-04 between 0 and 170 kbar. Our data are in good agreement with the previous ICE work on LX-04 [2] within their range of mutual overlap (up to 100 kbar). However our extended data range shows a less stiff response beyond $100 \mathrm{kbar}$ than the extrapolated Hugoniot derived from the previous work would suggest. Hydrodynamic simulations using the Trac II code further support this conclusion.

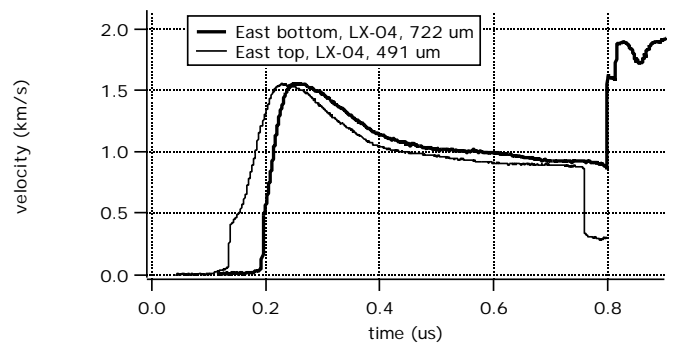

FIGURE 3. An EOS pair of LX-04 samples. The lack of amplitude growth at the peak and in the following rarefaction is evidence for insignificant reaction.

Figure 5 shows a comparison of the room temperature isotherm of pure HMX [9] to our LX-04 results. The isotherm appears to be slightly stiffer than our Hugoniot. We claim that the difference is due to the $15 \%$ binder composition of LX-04. We do not know of any EOS data for Viton-A in the literature but we did plot the Hugoniot for the somewhat similar Teflon [10]. Clearly the incorporation of $15 \%$ of a soft Teflon-like material will soften the mixture's P-V curve relative to pure HMX.

\section{SUMMARY AND FUTURE WORK}

We used the ICE technique and the improved pulse shaping capabilities of the $\mathrm{Z}$ machine at SNL to measure the unreacted 
approximate isentrope of full density LX-04 to 170 kbar, $70 \%$ higher than previous work. From our data we compute an unreacted Hugoniot for LX-04 given by $U_{\mathrm{S}}=2950 \mathrm{~m} / \mathrm{s}+$ (1.69) $u_{\mathrm{P}}$. This data is reasonably consistent with existing HMX isotherm data.

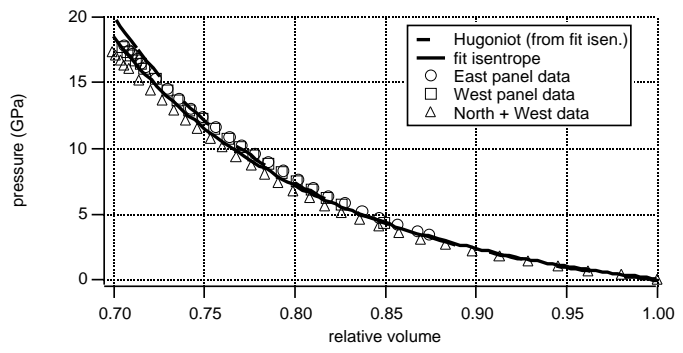

FIGURE 4. Results of this work: LX-04 isentrope data, fitted isentrope, and Hugoniot derived from this fitted isentrope. The derived Hugoniot parameters are $\mathrm{A}=2950 \mathrm{~m} / \mathrm{s}, \mathrm{B}=1.69$. Note pressure units are $\mathrm{GPa}$ on the graphs. Our estimate of uncertainty is $+/-5 \%$ in $P$ at a given relative volume.

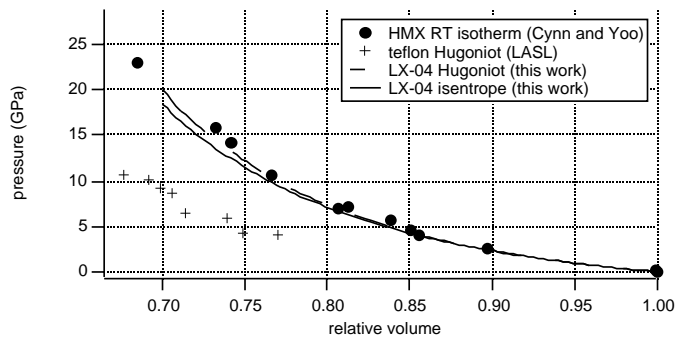

FIGURE 5. Comparison of HMX room temperature isotherm (Ref. 9), Teflon Hugoniot (Ref. 10), and the fitted LX-04 isentrope and its derived Hugoniot (this work).

We are hopeful that future advances will allow us to extend the pressure range on this and other HEs. We hope to have some Viton-A EOS data available in the near future so that detailed comparisons can be made between pure HMX data and LX-04 data.

\section{ACKNOWLEDGEMENTS}

This work would not have happened without the assistance of LeRoy Green, Scott Humphery, Kevin Vandersall, and Allen Elsholz from LLNL; and from SNL: Jean-Paul Davis, Chuck Hardjes, Dave Bliss, Josh Mason and the outstanding technical staff of the $\mathrm{Z}$ Machine facility. DEH would like to acknowledge helpful discussions with Dennis Hayes of SNL, and LeRoy Green, Ed Lee, Craig Tarver, and Paul Urtiew of LLNL.

This work was performed under the auspices of the U. S. Department of Energy by the University of California, Lawrence Livermore National Laboratory under Contract No. W7405-Eng-48.

\section{REFERENCES}

1. Owens, C., Nissen, A., and Souers, P.C., "LLNL Explosives Reference Guide" UCRL-WEB145045 (2003).

2. Reisman, D.B., et.al., in "Shock compression of condensed matter-2001, edited by M.D. Furnish, N.N. Thadhani, and Y. Horie. (AIP, Melville NY, 2002) p.849.

3. Reisman, D.B., et. al., in " 12 th International Detonation Symposium” San Diego CA, 2002.

4. Hall, C.A., Phys. Plasmas 7, 2069 (2000).

5. Reisman, D.B. et. al, J. Appl. Phys. 89, 1625 (2001).

6. Wackerle, J. and Stacy, H.L., "Shock waves in condensed matter, 1987" edited by Schmidt, S.C. and Holmes, N.C. (North Holland, New York, 1988).

7. Fowels, R. and Williams, R.F., J. Appl. Phys. 41, 360 (1970).

8. Hayes, D.B., "Backwards Integration of the Equations of Motion to Correct for Free Surface Perturbations", Sandia National Laboratories Report, SAND2001-1440(2001).

9. Yoo, C.S. and Cynn, H., J. Chem Phys. 1ll, 10229 (1999).

10. "LASL Shock Hugoniot Data", edited by S.P. Marsh (U. California Press, Berkeley, 1980). p.467 